Cláudio Viveiros de Carvalho ${ }^{1}$

Diva Barnabé Duarte 2

Edgar Merchán-Hamann 3

Eliana Bicudo 4

Josué Laguardia 5

\section{Determinantes da aderência à terapia anti-retroviral combinada em Brasília, Distrito Federal, Brasil, 1999-2000}

\author{
Predictors of compliance with highly active \\ antiretroviral therapy in Brasilia, Distrito Federal, \\ Brazil, 1999-2000
}

1 Câmara dos Deputados. Ed. Ax, Praça dos Três Poderes, Brasília, DF 70100-000, Brasil.

2 Caixa Econômica Federal. SBS Q01, Bloco L, Ed. Caixa Econômica Federal, Brasília, DF 70070-100, Brasil.

3 Departamento de Saúde Coletiva, Faculdade de Ciências da Saúde, Universidade de Brasília. C. P. 4370, Campus Universitário Darcy Ribeiro, Brasília, DF 70910-900, Brasil. hamann@unb.br ${ }^{4}$ Centro de Saúde no 1 , Hospital-Dia. Entrequadras 508/509, Asa Sul. Brasília, DF 70351-580, Brasil.

5 Departamento de Atenção Básica, Secretaria de Políticas de Saúde. Ministério da Saúde. Esplanada dos Ministérios, Bloco G, Brasília, DF 70058-901, Brasil.

\begin{abstract}
Non-compliance with highly active antiretroviral therapy can reduce treatment efficacy and lead to viral resistance. Side effects can interfere with patients' quality of life. Our objectives were to estimate levels of treatment compliance and investigate the main predictors of non-compliance. The study design was cross-sectional. For purposes of comparison, two different percentage cut-offs for compliance were defined for "proper compliance", namely the adequate ingestion of at least $80 \%$ or 95\% of the prescribed medicines, respectively. Semi-structured interviews were performed in a sequential sample of 150 patients during out-patient visits to the Day Hospital in Central Brasilia. Mean compliance was $85.8 \%$. Variables associated with noncompliance were age, schooling, employment status, monthly personal and family income, illegal substance use, family and community structure, presence of opportunistic infections when HIV was diagnosed, and treatment side effects. Prevalence ratios varied from 1.6 to 4.5. We conclude that social and economic variables, as well as those related to individual habits, were the main predictors of compliance. Few variables related to clinical status or treatment were associated with compliance.
\end{abstract}

Key words Acquired Immunodeficiency Syndrome; Patient Compliance; Highly Active Antiretroviral Therapy

Resumo A aderência ao tratamento é um dos principais problemas relacionados à terapia antiretroviral, já que a tomada incompleta dos medicamentos pode levar à resistência viral. Efeitos colaterais podem interferir com a qualidade de vida dos pacientes. Buscou-se estimar níveis de aderência à terapia e investigar seus determinantes, através de um estudo transversal. Definiramse dois pontos de corte como boa aderência: a tomada de pelo menos $80 \%$ ou de 95\% da medicação conforme a prescrição. Realizaram-se entrevistas semi-estruturadas em uma amostra seqüencial de 150 pacientes atendidos no Hospital-Dia de Brasília. Observou-se que a média de aderência foi $85,8 \%$. As variáveis que se mostraram significativamente associadas à baixa aderência foram: idade, escolaridade, situação de emprego, rendas pessoal e familiar, uso de substâncias ilícitas, estrutura familiar elou comunitária, presença de infecção oportunista no momento do diagnóstico e ocorrência de efeitos colaterais relacionados à terapia. As razões de prevalência variaram de 1,6 a 4,5. Concluiu-se que variáveis sócio-econômicas e de hábitos tiveram maior força de associação com o nível de aderência do que as relacionadas com a doença ou com o tratamento.

Palavras-chave Síndrome da Imunodeficiência Adquirida; Cooperação do Paciente; Terapia Anti-Retroviral de Alta Atividade 


\section{Introdução}

Atualmente, um dos principais problemas em relação à terapia da AIDS é a questão da aderência ao tratamento. Vêm sendo desenvolvidas, em especial nos últimos cinco anos, várias drogas anti-retrovirais que mostram grande eficácia na inibição do ciclo de reprodução viral, reduzindo significativamente a gravidade das manifestações da doença. Informações de estudos realizados em vários países, incluindo o Brasil, efetuados em âmbito clínico (Wolff et al., 2001), multi-institucional (Egger et al., 1997; Mocroft et al., 2002; Mouton et al., 1997; Palella Jr. et al., 1998) ou com dados de base populacional (Bonnet et al., 2002; Fonseca \& Barreira, 2000) indicam uma diminuição importante em vários indicadores de morbidade e mortalidade de pacientes com HIV/AIDS, após a introdução da terapia anti-retroviral combinada incorporando medicamentos inibidores de protease. Tais observações coincidem com aumentos relevantes na sobrevida e melhora da qualidade de vida dessas pessoas (Lee et al., 2001). Apesar da alta eficácia da terapia antiretroviral combinada, a efetividade tem sido prejudicada em virtude das dificuldades que os pacientes enfrentam para cumprir o tratamento corretamente. Aumentar a aderência dos pacientes ao tratamento anti-retroviral constitui uma questão de primeira ordem no combate à evolução da epidemia.

Adotamos o termo aderência seguindo a definição de Eldred (Eldred, 1997, apud Santos et al., 2000), que a considera como o grau em que o comportamento do paciente em relação à sua saúde corresponde à prescrição médica.

$O$ percentual de aderência real dificilmente chega a $100 \%$, uma vez que os esquemas propostos interferem diretamente na vida cotidiana do paciente, dificultando as tomadas dos medicamentos. Também questões emocionais interferem diretamente no uso da medicação, afetando sua capacidade de aderência ao tratamento (Paiva et al., 2000).

Existem vários métodos e técnicas desenvolvidos para avaliar a aderência ao tratamento em doenças crônicas, alguns se valendo de recursos tecnológicos bastante sofisticados, mas nenhum com acurácia perfeita para definir a real situação. Métodos com base no relato dos pacientes vêm sendo utilizados em estudos como este, devido à sua simplicidade, fidedignidade e baixo custo. No entanto, devem-se considerar sempre a ocorrência de vieses de memória e a necessidade de adequação cultural para situações diversas. De qualquer forma, tal metodologia tem se mostrado útil na avaliação da aderência a tratamentos crônicos (Paiva et al., 2000; Sumartojo, 1993).

Não existem estudos que definam o nível de aderência aceitável para o tratamento anti-retroviral. Na década passada, muitos autores utilizavam o nível de 80\% (Gray et al., 1998; Nemes et al., 2000). Paterson et al. (1999, apud Riera et al., 1999) conduziram um trabalho em que se avaliou a aderência mediante a contagem eletrônica de pílulas consumidas ao longo de três meses, obtendo resultados que provam uma relação direta entre os níveis de aderência e a supressão viral. Segundo estes autores, níveis próximos a 95\% de aderência apresentariam supressão da replicação viral substancialmente maior do que apenas de $80 \%$ de aderência. Devido à emergência relativamente freqüente de cepas resistentes com níveis de adesão inferiores a $90 \%$, consideramos, como o mais adequado, o parâmetro de $95 \%$. Relatamos, também, o de $80 \%$ apenas para efeitos de comparação com outros estudos, em especial com aquele desenvolvido no Estado de São Paulo por Nemes et al. (2000).

Ressaltamos que uma aderência adequada é fundamental. Falhas no tratamento podem levar ao desenvolvimento de resistência viral, diminuindo as possibilidades de ulteriores recursos terapêuticos para o paciente. Além da disseminação de cepas virais resistentes (Condra \& Emini, 1997; Hirsch et al., 1999), é também importante o fato de os medicamentos utilizados apresentarem um custo extremamente alto, tornando imperioso que seu fornecimento e uso sejam acompanhados criteriosamente, a fim de evitar desperdício de recursos públicos.

Este trabalho visa avaliar o grau de aderência ao tratamento anti-retroviral em um serviço especializado de referência em Brasília, bem como os seus fatores determinantes.

\section{Metodologia}

Em um estudo epidemiológico analítico do tipo transversal, colheram-se dados de 150 pacientes com AIDS que fazem uso de medicação anti-retroviral no Centro de Saúde no 1/Hospital-Dia de Brasília. Os dados foram obtidos por meio de entrevistas semi-estruturadas e da análise dos prontuários de setembro a dezembro de 1999.

O Centro de Saúde no 1/Hospital Dia é o centro de referência para o tratamento de DST/ AIDS no Distrito Federal com maior volume de atendimentos, acompanhando, à época da pesquisa, cerca de 750 pacientes de AIDS. A maioria é acompanhada no ambulatório, mas cerca 
de dez pacientes fazem tratamentos para infecções oportunistas no Hospital-Dia. Como o atendimento no serviço se dá mediante o comparecimento espontâneo dos pacientes, sem agendamento prévio, decidiu-se pela escolha de uma amostra seqüencial de pacientes, e não aleatória.

A participação no trabalho foi voluntária, com consentimento verbal dos 150 participantes. Houve apenas três pacientes contactados que não concordaram em ser entrevistados. Nenhum nome de paciente nem código de prontuário foram registrados nos instrumentos da pesquisa. Garantiu-se, aos pacientes a confidencialidade em relação às informações obtidas mediante entrevista e análise do prontuário. Além da entrevista, não foram realizados outros procedimentos junto aos pacientes.

Dois pesquisadores realizaram as entrevistas, em dias e horários diferentes, não fixos, incluindo todos as possibilidades de horários de atendimento. O questionário foi elaborado com a contribuição de idéias obtidas a partir dos instrumentos construídos por Lemes (1998) e Vale (1999).

A aderência constituiu a principal variável de desfecho (outcome variable). Foi estimada considerando o relato do número de comprimidos tomados por dia, desde o início do tratamento anti-retroviral, calculando-se o percentual de comprimidos ingeridos em relação ao total prescrito. Consideraram-se, como parâmetros de aderência, como já citado, dois níveis: $80 \%$ e $95 \%$.

Tanto na entrevista como na revisão de prontuários, a maioria das variáveis foi registrada como perguntas fechadas. As registradas como perguntas abertas estiveram relacionadas com características ou eventos tais como idade, local de nascimento e residência, tipo de substância utilizada, doença oportunista, contagem de CD4 e de carga viral e efeitos colaterais, dentre outras. Tais variáveis foram posteriormente agrupadas em classes ou categorias e/ou codificadas quando pertinente. Também recolheram-se, do prontuário, parâmetros clínicos tais como a presença de infecções oportunistas em três momentos distintos - no momento do diagnóstico, um ano antes da entrevista e no momento da mesma - e laboratoriais - CD4 e carga viral. Após a transformação logarítmica da carga viral, calculou-se a média geométrica. O critério de melhora ou piora desse parâmetro foi concebido em decorrência de alterações superiores a 1 log.

Análises estatísticas bivariadas entre a variável dependente - percentual de aderência e as variáveis preditoras foram realizadas, sen- do calculados a razão de prevalência para cada variável, o intervalo de confiança de $95 \%$ e o teste de Mantel-Haenszel para cada relação, considerando-se o valor $\mathrm{p}<0,05$ como nível de significância. Utilizaram-se os programas Excel e Epi Info para o registro e a análise dos dados obtidos.

Realizou-se a regressão logística, determinando-se a aderência no nível de $95 \%$ como variável resultante. As variáveis incluídas no modelo corresponderam àquelas que mostraram significância estatística na análise bivariada além do sexo. O método utilizado foi o de Conditional Forward Stepwise. Calcularam-se, para cada variável a razão de chances (odds ratio), intervalo de confiança e a verossimilhança e os respectivos testes de significância foram aplicados. Efetuou-se a análise de regressão utilizando-se o SPSS 10.0.

\section{Resultados}

\section{Características demográficas \\ e sócio-econômicas}

Entrevistaram-se 150 pacientes, com predomínio do sexo masculino $(66,7 \%)$. A idade variou de 14 a 56 anos, com média de 36,2 anos e mediana 35 anos.

A categoria predominante de estado civil foi de solteiros (62\%), seguidos dos casados $(26,7 \%)$. Entre as mulheres, $24 \%$ são casadas, $54 \%$ solteiras e $8 \%$ viúvas. Metade da amostra $(50,7 \%)$ não tem dependentes, e $42,6 \%$ têm de 1 a 3 dependentes. A média de dependentes foi de 1,2 por entrevistado.

Quanto ao local de moradia, 80,7\% são provenientes do Distrito Federal, 9,3\% da região do entorno de Brasília e $10 \%$ de outros estados (Goiás, Tocantins, Maranhão, Bahia). A maioria $(74,7 \%)$ reside com a família, $13,3 \%$ sozinhos, $4,7 \%$ em instituição, 3,3\% com amigos e $4 \%$ em outras situações (aqueles que referiram morar com o/a companheiro/a, mas que não os consideraram como sua família). A maioria, $69,3 \%$, refere residir em casa própria.

Em relação à escolaridade, apenas 2,7\% dos pacientes eram analfabetos. Houve proporções semelhantes de participantes com primeiro grau completo ou incompleto $(36,7 \%)$ e com segundo grau completo ou incompleto $(37,3 \%)$; $23,3 \%$ referiram nível superior completo ou incompleto.

A maior parte dos entrevistados tem uma renda fixa (62\%), 18,7\% estão desempregados e 19,3\% são autônomos. As ocupações mais freqüentes pertenciam à área financeira/adminis- 
trativa, como funcionários públicos e bancários $(21,3 \%)$, ao comércio (11,3\%), que, além de outras ocupações mencionadas pelas mulheres - empregada doméstica $(7,3 \%)$ e dona de casa $(6 \%)$-, totalizavam $46 \%$ da amostra.

A renda foi calculada levando em conta o salário mínimo (SM) em reais $(\mathrm{R} \$)$ à época, que era de $\mathrm{R} \$ 136,00$ (equivalente a cerca de US\$ 70,00). A renda pessoal variava de $\mathrm{R} \$ 0$ a $\mathrm{R} \$ 6.000,00$, com média de $\mathrm{R} \$ 839,14$ (6,2 SM) e mediana de $\mathrm{R} \$ 500,00$ (3,7 SM). A renda familiar varia de $\mathrm{R} \$$ 0 a $\mathrm{R} \$ 13.000,00$, com média de $\mathrm{R} \$ 1.489,38$ (11 $\mathrm{SM})$ e mediana de $\mathrm{R} \$ 1.000,00(7,4 \mathrm{SM})$.

Com relação aos hábitos e modo de vida, $37,3 \%$ dos pacientes entrevistados declararam que fazem uso de bebida alcoólica - dentre os quais caracterizou-se abuso em $23,2 \%$, considerando a freqüência e a quantidade de álcool ingerida - e 31,3\% relataram tabagismo. Já quanto ao uso de substâncias ilícitas, $18 \%$ relataram ser ou haver sido usuários, sendo a cocaína a mais utilizada $(55,2 \%)$, seguida da maconha $(37,9 \%)$. No último mês, $8,7 \%$ da amostra utilizaram substâncias ilícitas - 69,2\% deles, cocaína injetável e 30,8\%, maconha.

Quanto ao apoio social, 84,7\% dos entrevistados afirmaram que suas famílias sabem de seu diagnóstico, mas apenas $42,5 \%$ deles se sentem ajudados por elas. Já $58 \%$ afirmaram que seus amigos sabem, mas apenas $25,3 \%$ sentem que eles os ajudam a tomar a medicação.

\section{Características clínicas}

Encontrou-se uma distribuição homogênea na amostra em relação ao tempo de diagnóstico, sendo que 78,6\% têm menos de cinco anos de diagnóstico. A principal via presumível de infecção foi a sexual $(86,7 \%)$. Apenas 5,3\% referiram haver sido infectados pelo uso compartilhado de drogas injetáveis.

Cerca de um terço da amostra (32\%) teve definido o diagnóstico de HIV por apresentar infecções oportunistas. Destes, 64,6\% apresentavam apenas uma infecção e $29,2 \%$ duas infecções diferentes. Ainda, 68,8\% consideraram seu quadro clínico grave e $27,1 \%$, moderado. Os diagnósticos mais freqüentes naquele momento foram síndromes diarréicas e vômitos (26,5\%), pneumonias $(22,1 \%)$ e monilíase $(11,8 \%)$.

Analisaram-se a presença ou a ausência de infecções oportunistas desde a entrada ao serviço mas não sua gravidade. No momento da entrada no serviço, $50,7 \%$ da população participante apresentavam tais infecções, enquanto, no momento da entrevista, apenas 17,3\% apresentavam-nas. Em relação à evolução de tal parâmetro, comparando os registros presen- tes desde o ingresso ao serviço até o momento da entrevista, 30,7\% tiveram evolução positiva, passando a não apresentar mais infecções oportunistas, enquanto $63 \%$ mantiveram o status anterior, de presença ou ausência das mesmas; no entanto, destes, 92,5\% não apresentavam infecção no momento do diagnóstico e assim permaneceram, o que também se pode considerar evolução positiva.

Os diagnósticos de infecções oportunistas e de manifestações clínicas mais comuns no momento da entrada no serviço seguiram a tendência encontrada do momento do diagnóstico: diarréia/vômito (22,2\%), pneumonia (18,5\%) e monilíase (16,7\%). Há um ano, no entanto, o padrão se alterou, com predominância explícita de pneumonias $(55,6 \%)$. Atualmente, a distribuição está como a seguir: $28,6 \%$ de pneumonias, $19 \%$ de monilíase, $14,3 \%$ de diarréia/ vômito e $14,3 \%$ de outras infecções.

Além da análise da presença de infecções oportunistas, avaliou-se a caracterização do quadro clínico dos pacientes segundo dois parâmetros laboratoriais - carga viral e contagem de linfócitos CD4 - em três momentos distintos: no início do acompanhamento na instituição, cerca de um ano antes da entrevista realizada e à época da entrevista. A análise da evolução das médias geométricas da carga viral e das médias de contagens de CD4 nesses três momentos revelou que houve uma grande melhora nos parâmetros entre o momento de entrada no serviço e um ano atrás i.e., queda da carga viral e aumento de CD4. Porém, houve uma tendência leve de reversão desta melhora no momento da pesquisa.

Houve grande variação na carga viral e na contagem de CD4 nos três momentos. Analisando a evolução dos dois parâmetros e comparando o primeiro registro constante no prontuário dos pacientes com o registro do momento da entrevista, encontramos predomínio de evolução positiva na amostra. Houve melhora em $55,6 \%$ para carga viral e $68,8 \%$ para o CD4.

Solicitados a descrever qual esquema antiretroviral vêm seguindo, 89,3\% informaram esquema correto em relação aos dados de prescrição constantes no prontuário, 6,7\% relataram estar tomando medicações diferentes das prescritas e $4 \%$ não souberam informar. Quanto à posologia prescrita, $86,7 \%$ relataram-na em conformidade com o prontuário, $10 \%$ em desacordo com este e 3,3\% não souberam descrevê-la.

Cerca de metade dos pacientes $(49,3 \%)$ referiram apresentar algum efeito colateral da medicação anti-retroviral, principalmente náusea e vômitos $(31,1 \%)$, diarréia (12,9\%), epigastralgia $(11,2 \%)$ e cefaléia $(10,6 \%)$. 
Na amostra, 42,7\% dos entrevistados referem uso regular de outras medicações que não os anti-retrovirais. Os medicamentos mais relatados foram sulfonamidas $(19,6 \%)$, medicamentos relacionados ao sistema cardiovascular $(12,5 \%)$ e psicotrópicos $(8,9 \%)$. Dentre tais medicações não-anti-retrovirais, $48,3 \%$ do total têm uso indicado para o tratamento de infecções oportunistas.

Quanto ao antecedente de falha terapêutica prévia, 114 pacientes referiram já haver falhado com a medicação em algum momento desde o início do tratamento ( $76 \%$ da amostra). Os principais motivos alegados foram esquecimento, rejeição e presença de efeitos colaterais.

\section{Níveis de aderência e análise} dos fatores de risco/proteção

O percentual de aderência ao tratamento variou de $0 \%$ (em $7,2 \%$ da amostra) a $100 \%$ (em $32 \%$ ), com valor médio de $85,8 \%$ e mediana de 99\%. Quanto à distribuição da aderência, $76 \%$ dos pacientes relataram níveis iguais ou superiores a $95 \%$, e $83,2 \%$ iguais ou superiores a $80 \%$.

Pode-se verificar, nas Tabelas 1, 2 e 3, a análise dos fatores de risco para a não-aderência considerando os dois pontos de corte para a boa aderência. Ressalta-se que não houve grandes diferenças entre os resultados estatisticamente significantes para os dois níveis de aderência estudados. Em geral, em relação às variáveis sócio-econômicas e demográficas que se mostraram associadas à não aderência (Tabela 1), conclui-se que indivíduos menores de 35 anos e de baixa escolaridade constituem as categorias com maior risco. O desemprego mostrou-se associado como fator de risco e o emprego, como fator protetor. As variáveis de renda pessoal e familiar também demonstraram associações significativas com a não-aderência.

Quanto ao uso de substâncias, modo de vida e apoio social (Tabela 2), as variáveis mais destacadas foram: o consumo recente ou passado de substâncias de uso ilegal, o tabagismo e a associação desses hábitos com o consumo de álcool. A moradia em instituição também mostrou-se associada à não-aderência.

A análise de variáveis relacionadas ao estado clínico (Tabela 3) revelou que a presença de infecção no momento do diagnóstico esteve associada a uma maior aderência. Quanto às variáveis relacionadas ao tratamento (Tabela 4), a presença de efeitos colaterais mostrou-se associada à aderência menor de $80 \%(\mathrm{RP}=1,96$; IC $95 \%=1,02-3,78$; valor $\mathrm{p}=0,03)$ e também menor de 95\% (RP = 1,7; IC 95\% = 1,05-2,79; va- lor $\mathrm{p}=0,02)$. Já o uso de outros medicamentos não mostrou associação significante com os dois níveis de não-aderência estudados: $<80 \%$ $(\mathrm{RP}=1,42$; IC 95\% = 0,74-2,73; valor $\mathrm{p}=0,28) \mathrm{e}$ $<95 \%(\mathrm{RP}=1,24$; IC 95\% = 0,76-2,02; valor $\mathrm{p}=$ $0,38)$. Tampouco houve aumento significativo da ocorrência de efeitos colaterais devido ao uso de outras medicações (RP = 1,21; IC 95\% = 0,87-1,66; valor p: 0,26).

Analisando a influência exercida pelo percentual de aderência sobre a evolução dos parâmetros clínicos (Tabela 5), observamos que uma boa aderência se mostrou como preditor associado à evolução positiva para a presença de infecções oportunistas somente para o ponto de corte de $80 \%$, não para o de $95 \%$. Para os outros parâmetros clínicos (contagem de CD4 e carga viral), no entanto, não foi observada diferença estatisticamente significante.

A análise da evolução dos parâmetros clínicos de acordo com as variáveis de uso dos medicamentos anti-retrovirais "de acordo com o prescrito no prontuário" e "com posologia de acordo com o prescrito no prontuário" encontra-se na Tabela 5. De novo, verificou-se a associação com a presença de infecções oportunistas, e não com níveis de CD4 e carga viral.

Realizou-se a análise de regressão logística incluindo-se, na equação, as seguintes variáveis: idade, sexo, escolaridade, rendas familiar e pessoal, situação de emprego, situação de residência, presença de infecção oportunista no diagnóstico, uso de drogas ilícitas e freqüência de consumo das mesmas. Duas variáveis permaneceram no modelo, mostrando significância estatística $(p<0,00001)$ : a renda familiar ganhar menos de $3 \mathrm{SM}$ tem maior probabilidade de não-aderência (OR $=11,0$; IC 95\% = 3,8$31,6)$ - e a utilização de substâncias ilícitas $(\mathrm{OR}=9,0 ; \mathrm{IC} 95 \%=2,8-28,5)$.

\section{Discussão}

Analisando os resultados obtidos, notamos que não houve diferenças importantes entre as associações observadas com a aderência/nãoaderência segundo os dois pontos de corte definidos. Mesmo entre as variáveis que mostraram diferentes resultados de significância estatística, os valores se encontram bastante próximos do limite estabelecido.

No conjunto dos diversos grupos de variáveis, mostram-se, com maior peso para a definição da aderência ao tratamento anti-retroviral na análise bivariada não ajustada, os preditores sócio-econômicos e demográficos. A razão de sexo e a distribuição segundo idade es- 
Tabela 1

Análise dos fatores de risco para não-aderência ao tratamento anti-retroviral entre os pacientes de AIDS

no Centro de Saúde no1/Hospital-Dia, considerando os percentuais de aderência de $80 \%$ e de $95 \%$.

Distrito Federal, Brasil, 1999-2000.

\begin{tabular}{|c|c|c|c|c|c|c|c|c|}
\hline \multirow{2}{*}{$\begin{array}{l}\text { Variáveis sócio-econômicas } \\
\text { e demográficas }\end{array}$} & \multicolumn{4}{|c|}{$80 \%$} & \multicolumn{4}{|c|}{$95 \%$} \\
\hline & RP & IC 95\% & $\mathrm{p}$ & Significante & $\mathrm{RP}$ & IC $95 \%$ & $p$ & Significante \\
\hline \multicolumn{9}{|l|}{ Sexo } \\
\hline Feminino vs. masculino & 1,6 & $0,9-2,9$ & 0,15 & Não & 1,3 & $0,8-2,1$ & 0,26 & Não \\
\hline \multicolumn{9}{|l|}{ Idade } \\
\hline$<35$ anos vs. $\geq 35$ anos & 2,5 & $1,2-5,0$ & 0,007 & $\operatorname{Sim}$ & 1,6 & $1,0-2,6$ & 0,047 & Sim \\
\hline \multicolumn{9}{|l|}{ Estado civil } \\
\hline Casado vs. outros & 1,1 & $0,5-2,1$ & 0,83 & Não & 0,9 & $0,5-1,6$ & 0,75 & Não \\
\hline Solteiro vs. outros & 1,2 & $0,6-2,2$ & 0,6 & Não & 1,2 & $0,7-2,0$ & 0,42 & Não \\
\hline \multicolumn{9}{|l|}{ Dependentes } \\
\hline 0 vs. $\geq 1$ & 1,2 & $0,6-2,2$ & 0,63 & Não & 1,3 & $0,7-1,8$ & 0,65 & Não \\
\hline \multicolumn{9}{|l|}{ Endereço } \\
\hline Plano Piloto* vs. outros & 0,8 & $0,3-1,7$ & 0,49 & Não & 0,7 & $0,3-1,3$ & 0,19 & Não \\
\hline Cidades satélites vs. outros & 0,8 & $0,5-1,6$ & 0,6 & Não & 1,1 & $0,7-1,8$ & 0,60 & Não \\
\hline Entorno/outros Estados vs. outros & 1,6 & $0,8-3,1$ & 0,16 & Não & 1,2 & $0,7-2,1$ & 0,45 & Não \\
\hline \multicolumn{9}{|l|}{ Condição de moradia } \\
\hline Própria vs. outros & 0,7 & $0,4-1,4$ & 0,35 & Não & 0,9 & $0,5-1,4$ & 0,63 & Não \\
\hline \multicolumn{9}{|l|}{ Escolaridade } \\
\hline Analfabeto vs. outros & 3,8 & $2,0-7,2$ & 0,008 & Sim & 2,4 & $1,3-4,5$ & 0,06 & Não \\
\hline Até 1ㅇ grau vs. 2o e 3o graus & 2,2 & $1,2-4,2$ & 0,009 & Sim & 2,3 & $1,5-3,8$ & 0,0003 & Sim \\
\hline Até 2o grau vs. 3o grau & 4,6 & $1,1-18,1$ & 0,01 & Sim & 4,6 & $1,5-13,8$ & 0,0007 & $\operatorname{Sim}$ \\
\hline \multicolumn{9}{|l|}{ Situação de emprego } \\
\hline Fixo vs. outros & 0,4 & $0,2-0,96$ & 0,02 & Sim & 0,4 & $0,2-0,8$ & 0,006 & Sim \\
\hline Desempregado vs. outros & 2,3 & $1,2-4,2$ & 0,01 & Sim & 2,2 & $1,4-3,4$ & 0,001 & Sim \\
\hline Autônomo vs. outros & 1,4 & $0,7-2,8$ & 0,36 & Não & 1,2 & $0,7-2,1$ & 0,45 & Não \\
\hline \multicolumn{9}{|l|}{ Renda pessoal (salários mínimos) } \\
\hline$<3$ vs. $\geq 3$ & 3,8 & $1,9-7,7$ & 0,00004 & Sim & 2,5 & $1,5-4,1$ & 0,0001 & $\operatorname{Sim}$ \\
\hline$<3$ vs. $\geq 3$ & 3,7 & $1,9-7,1$ & 0,00002 & Sim & 3,0 & $1,8-4,7$ & 0,000003 & Sim \\
\hline
\end{tabular}

RP = Razão de prevalência; IC 95\% = Intervalo de confiança de 95\%.

* Incluem-se, juntamente com o Plano Piloto, os bairros Lagos Sul e Norte, o Park Way e o Cruzeiro.

tão de acordo com os dados oriundos da notificação do Brasil para o ano de 1999 (Coordenação Nacional de DST/AIDS, 2000) e demonstram a influência das mudanças do perfil epidemiológico ocorridas nas duas décadas prévias. Neste trabalho, a idade aparece como preditor de não-aderência. A variável sexo não mostrou associação estatística, embora tenha sido encontrada uma menor aderência entre mulheres que não atingiu significância, provavelmente devido ao tamanho da amostra. No entanto, em um estudo de caso-controle reali- zado em Taguatinga, Distrito Federal, com pacientes que, segundo critérios do serviço, haviam "abandonado" o tratamento anti-retroviral, houve predomínio de mulheres $-60 \%$ dos casos - quando comparados com controles i.e., os pacientes que não haviam abandonado a terapia (Vale, 1999). Chama a atenção o alto percentual de famílias que têm como provedor único a mulher $(76 \%)$, principalmente ao se considerar que $70 \%$ das mulheres da amostra têm pelo menos um dependente. Aspectos de vulnerabilidade relacionados aos papéis de gê- 
Análise dos fatores de risco para não-aderência ao tratamento anti-retroviral entre os pacientes de AIDS no Centro de Saúde no1/Hospital-Dia, considerando os percentuais de aderência de $80 \%$ e de $95 \%$. Distrito Federal, Brasil, 1999-2000.

\begin{tabular}{|c|c|c|c|c|c|c|c|c|}
\hline \multirow{2}{*}{$\begin{array}{l}\text { Variáveis relacionadas aos hábitos, } \\
\text { modo de vida e apoio social }\end{array}$} & \multicolumn{4}{|c|}{$80 \%$} & \multicolumn{4}{|c|}{$95 \%$} \\
\hline & RP & IC 95\% & $\mathrm{p}$ & Significante & RP & IC 95\% & $\mathrm{p}$ & Significante \\
\hline Uso de álcool & 1,3 & $0,7-2,4$ & 0,40 & Não & 1,2 & $0,7-1,9$ & 0,45 & Não \\
\hline Abuso de álcool & 1,8 & $0,7-4,5$ & 0,20 & Não & 1,8 & $0,9-3,5$ & 0,12 & Não \\
\hline Tabagismo & 1,1 & $0,6-2,2$ & 0,67 & Não & 1,7 & $1,1-2,7$ & 0,02 & Sim \\
\hline Uso de drogas ilícitas & 2,0 & $1,1-3,8$ & 0,03 & Sim & 1,9 & $1,2-2,9$ & 0,01 & Sim \\
\hline Drogas no último mês & 2,1 & $1,1-3,8$ & 0,02 & Sim & 1,9 & $1,2-3,0$ & 0,01 & Sim \\
\hline Álcool + fumo & 0,7 & $0,2-2,5$ & 0,54 & Não & 1,4 & $0,7-2,7$ & 0,37 & Não \\
\hline Álcool + drogas & 2,4 & $0,9-6,0$ & 0,11 & Não & 1,5 & $0,6-3,6$ & 0,45 & Não \\
\hline Fumo + drogas & 0,6 & $0,1-4,1$ & 0,62 & Não & 1,7 & $0,8-3,6$ & 0,21 & Não \\
\hline Álcool + fumo + drogas & 2,9 & $1,5-5,7$ & 0,01 & $\operatorname{Sim}$ & 2,2 & $1,3-3,8$ & 0,02 & $\operatorname{Sim}$ \\
\hline \multicolumn{9}{|l|}{ Estrutura familiar e/ou comunitária } \\
\hline Mora em instituição/sozinho vs. outros & 1,8 & $0,9-3,4$ & 0,09 & Não & 1,7 & $1,0-2,7$ & 0,047 & Sim \\
\hline Família vs. outros & 0,7 & $0,4-1,4$ & 0,38 & Não & 0,7 & $0,4-1,1$ & 0,12 & Não \\
\hline Apoio da família & 1,3 & $0,7-2,4$ & 0,46 & Não & 0,8 & $0,5-1,4$ & 0,46 & Não \\
\hline Apoio dos amigos & 0,6 & $0,2-1,9$ & 0,37 & Não & 1,0 & $0,5-2,0$ & 0,98 & Não \\
\hline
\end{tabular}

$\mathrm{RP}=$ Razão de prevalência; IC 95\% = Intervalo de confiança de 95\%.

Tabela 3

Análise dos fatores de risco para não-aderência ao tratamento anti-retroviral entre os pacientes de AIDS no Centro de Saúde no1/Hospital-Dia, considerando os percentuais de aderência de $80 \%$ e de $95 \%$. Distrito Federal, Brasil, 1999-2000.

\begin{tabular}{|c|c|c|c|c|c|c|c|c|}
\hline \multirow{2}{*}{$\begin{array}{l}\text { Variáveis relacionadas à caracterização } \\
\text { da doença e do estado clínico }\end{array}$} & \multicolumn{4}{|c|}{$80 \%$} & \multicolumn{4}{|c|}{$95 \%$} \\
\hline & $\mathrm{RP}$ & IC 95\% & $\mathrm{p}$ & Significante & $\mathrm{RP}$ & IC 95\% & $p$ & Significante \\
\hline $\begin{array}{l}\text { Tempo de diagnóstico } \\
\text { (<5 anos vs. } \geq 5 \text { anos) }\end{array}$ & 0,7 & $0,3-1,6$ & 0,38 & Não & 0,6 & $0,3-1,3$ & 0,17 & Não \\
\hline $\begin{array}{l}\text { Via presumível de infecção } \\
\text { (sangüínea vs. sexual) }\end{array}$ & 1,2 & $0,5-2,8$ & 0,66 & Não & 0,8 & $0,3-1,7$ & 0,47 & Não \\
\hline Presença de infecção no diagnóstico & 0,3 & $0,1-1,2$ & 0,10 & Não & 0,3 & $0,1-0,8$ & 0,01 & $\operatorname{Sim}$ \\
\hline $\begin{array}{l}\text { Intensidade da infecção no diagnóstico } \\
\text { (leve/moderado vs. grave) }\end{array}$ & 0,9 & $0,3-2,7$ & 0,89 & Não & 1,3 & $0,7-2,5$ & 0,48 & Não \\
\hline $\begin{array}{l}\text { Carga viral no momento do diagnóstico } \\
\text { (< } 100.000 \text { cópias vs. } \geq 100.000 \text { cópias) }\end{array}$ & 1,3 & $0,7-2,4$ & 0,45 & Não & 0,9 & $0,6-1,4$ & 0,67 & Não \\
\hline $\begin{array}{l}\text { CD4 no momento do diagnóstico } \\
\text { (<350 células/ml vs. } \geq 350 \text { células } / \mathrm{ml})\end{array}$ & 1,5 & $0,7-3,4$ & 0,29 & Não & 1,8 & $0,9-3,4$ & 0,07 & Não \\
\hline
\end{tabular}

$\mathrm{RP}=$ Razão de prevalência; IC 95\% = Intervalo de confiança de 95\%. 
Tabela 4

Análise da relação entre a não-aderência ao tratamento anti-retroviral e a evolução da carga viral, da contagem de CD-4 e das infecções oportunistas dos pacientes de AIDS no Centro de Saúde nô1/Hospital-Dia, considerando os percentuais de não-aderência de $80 \%$ e 95\%. Distrito Federal, Brasil, 1999-2000.

\begin{tabular}{|c|c|c|c|c|c|c|c|c|}
\hline & \multicolumn{4}{|c|}{$80 \%$} & \multicolumn{4}{|c|}{$95 \%$} \\
\hline & $\mathrm{RP}$ & IC $95 \%$ & $\mathrm{p}$ & Significante & $\mathrm{RP}$ & IC 95\% & p & Significante \\
\hline Evolução da carga viral (melhora vs. piora) & 0,9 & $0,5-1,6$ & 0,61 & Não & 0,7 & $0,4-1,3$ & 0,24 & Não \\
\hline Contagem de CD4 (melhora vs. piora) & 1,4 & $0,8-2,5$ & 0,32 & Não & 1,2 & $0,7-2,1$ & 0,47 & Não \\
\hline $\begin{array}{l}\text { Evolução das infecções oportunistas } \\
\text { (melhora vs. piora) }\end{array}$ & 4,8 & $1,3-7,6$ & 0,01 & Sim & 2,4 & $0,6-9,2$ & 0,18 & Não \\
\hline
\end{tabular}

RP = Razão de prevalência; IC 95\% = Intervalo de confiança de 95\%.

Análise da relação entre as variáveis de uso dos medicamentos "de acordo com o prontuário" e "com posologia de acordo o prontuário" e a evolução da carga viral, da contagem de CD-4 e das infecções oportunistas dos pacientes de AIDS no Centro de Saúde no1/Hospital-Dia. Distrito Federal, Brasil, 1999-2000.

\begin{tabular}{|c|c|c|c|c|c|c|c|c|}
\hline & \multicolumn{4}{|c|}{$\begin{array}{l}\text { Consumo de medicamento } \\
\text { "de acordo com o prontuário" }\end{array}$} & \multicolumn{4}{|c|}{$\begin{array}{l}\text { Posologia "de acordo } \\
\text { com o prontuário" }\end{array}$} \\
\hline & $\mathrm{RP}$ & IC 95\% & $p$ & Significante & $\mathrm{RP}$ & IC $95 \%$ & $p$ & Significante \\
\hline Evolução da carga viral & 0,8 & $0,3-2,1$ & 0,67 & Não & 0,7 & $0,3-1,9$ & 0,47 & Não \\
\hline Contagem de CD-4 & 0,7 & $0,2-2,5$ & 0,59 & Não & 0,6 & $0,2-2,3$ & 0,47 & Não \\
\hline Evolução das infecções oportunistas & 1,8 & $0,2-13,4$ & 0,55 & Não & 4,3 & $1,0-18,3$ & 0,044 & Sim \\
\hline
\end{tabular}

$\mathrm{RP}=$ Razão de prevalência; IC 95\% = Intervalo de confiança de 95\%.

nero podem estar afetando preferencialmente as mulheres.

O fato de cerca de $20 \%$ da população atendida no Centro de Saúde no 1/Hospital-Dia ser proveniente da região do entorno de Brasília ou mesmo de outros estados é um dado importante, e deve ser levado em conta ao se estabelecerem metas com relação à população alvo do serviço. Além disso, dentre aqueles que residem no Distrito Federal, existe uma população significativa de pessoas provenientes de locais servidos por outros centros de referência para o tratamento de HIV/AIDS que buscaram atendimento no Plano Piloto. Concordamos com Vale (1999) em que um dos motivos que podem justificar esses fatos é a possibilidade de as pessoas procurarem atendimento em um local onde haja menor probabilidade de serem identificadas, preservando-se de eventuais constrangimentos.

Morar sozinho ou em instituição foi um fator de risco para não-aderência, considerando o ponto de corte de $95 \%$ na análise bivariada.
Quanto a este fator, não há consenso na literatura. Em estudos como o de Riera et al. (1999), verificou-se menor aderência entre os que vivem com os pais. Em nosso meio, trabalho prévio demonstra uma menor aderência nos moradores de instituições ou sozinhos (Vale, 1999). Ainda não foi verificada diferença significativa entre os grupos relacionada ao apoio social proporcionado pela família ou por amigos, o que está em consonância com o descrito por outros autores (Riera et al., 1999).

Quanto à distribuição dos pacientes por nível de escolaridade, o padrão encontrado se mostra bastante diferente do geral para o Brasil, que atualmente se caracteriza por uma freqüência muito maior entre pessoas que têm apenas o primeiro grau do que entre a população com maior nível de escolaridade (Coordenação Nacional de DST/AIDS, 2000). Mesmo assim, o nível de escolaridade apresentou-se como uma variável preditora na análise bivariada para todos os pontos de corte analisados, demonstrando-se menor aderência no grupo 
com baixo grau de instrução, em consonância com a literatura (Nemes et al., 2000).

Mostraram-se como fatores de risco importantes para baixa aderência tanto a situação de emprego, quanto os níveis de renda pessoal e familiar. Ter um emprego fixo apresentou-se como fator de proteção para baixa aderência, ao passo que estar desempregado mostrou ser fator de risco. Já a renda, considerando o ponto de corte escolhido, apresentou também associação com o nível de aderência. A renda familiar foi o fator mais importante na análise multivariada. Esses fatos, aliados à influência do nível de escolaridade já mencionado, apontam como determinante fundamental a condição socioeconômica dos pacientes. Ainda que não haja consenso na literatura quanto ao papel exercido pelos fatores socioeconômicos, vemse encontrando associação entre tais fatores e a aderência ao tratamento anti-retroviral (Jordan et al., 2000; Nemes et al., 2000; Vale, 1999).

O uso de substâncias ilícitas - atual ou no passado - mostrou associação com a aderência nos seus dois pontos de corte e permaneceu como variável significativa na análise multivariada. Tampouco há consenso quanto a este fator na literatura, o que se pode dever às diversidades locais. Em estudos como os de Riera et al. (1999) e Vale (1999), demonstrou-se que utilizar estas substâncias altera o nível de aderência. Já outros pesquisadores afirmam que esta associação não se mantém mediante a análise multivariada. Para alguns autores, apenas a utilização ativa de substâncias de uso ilícito principalmente as ditas "pesadas", como a cocaína e o crack - está associada à diminuição do percentual de aderência ao esquema anti-retroviral (Nemes et al., 2000).

A influência do tabagismo mostrou-se significante apenas para o percentual de aderência de $95 \%$. O fato de o uso e o abuso de álcool não terem apresentado relevância estatística está em desacordo com o esperado, considerandose a literatura (Nemes et al., 2000; Riera et al., 1999). No entanto, muitos dos entrevistados referiram ter interrompido o uso do álcool após iniciar o tratamento anti-retroviral, o que pode justificar tal fato. O uso concomitante de álcool, tabaco e outras substâncias apresentou uma associação com a aderência maior do que o uso isolado de cada um ou do uso combinado de apenas dois deles.

A via de infecção presumível predominante foi a sexual, com freqüência bastante acima dos dados da população do Distrito Federal nos últimos anos $(42,1 \%)$ - dados que, no entanto, apresentam grande percentual sem informação (31,8\%). A transmissão por uso comparti- lhado de drogas injetáveis encontra-se em nível semelhante ao do Distrito Federal - 4,5\% dos casos (SES-DF, 2000).

Quanto às variáveis clínicas, chama a atenção seu menor poder de predição de baixa aderência. Apenas a presença de efeitos colaterais mostrou-se sempre associada com significância estatística. Já a presença de infecções no momento do diagnóstico demonstrou associação significativa apenas para o ponto de corte de $95 \%$.

A distribuição segundo o tempo transcorrido desde o diagnóstico mostrou maior freqüência para o grupo com mais de cinco anos. Ela difere daquela dos primeiros anos da epidemia, quando drogas anti-retrovirais eficazes e efetivas não eram disponíveis, e pode estar refletindo uma tendência ao aumento da sobrevida dos pacientes. De fato, tal tendência tem sido bem documentada em alguns países (Cascade Collaboration, 2000; Lee et al., 2001).

A presença de infecções oportunistas no momento do diagnóstico do HIV mostrou-se associada apenas para o ponto de corte de $95 \%$ de aderência. No entanto, a percepção do paciente quanto à gravidade dessas infecções não apresentou associação estatística com a aderência, ao contrário do referido por Jordan et al. (2000). Também os níveis da carga viral e do CD4 no momento da entrada no serviço não apresentaram associação significativa com o percentual de aderência.

A ausência de associação entre níveis de aderência e as variáveis laboratoriais da evolução da carga viral e do CD4 chamam a atenção, uma vez que se esperaria uma relação causaefeito (Riera et al., 1999). Cabe ressaltar que houve perda de dados desses parâmetros clíni$\cos (22 \%$ e $14,7 \%$, respectivamente), o que pode levar à diminuição do poder estatístico nos testes de hipóteses. Também o uso de medicamentos anti-retrovirais segundo a prescrição e o uso da posologia de acordo com o descrito no prontuário não mostraram relação com a evolução dos parâmetros laboratoriais. Apenas a evolução das infecções oportunistas apresentou fraca relação com a posologia das drogas anti-retrovirais relatada pelos pacientes.

A maior parte dos entrevistados refere lembrar-se automaticamente de tomar os medicamentos. No entanto, o principal motivo relatado para falha na medicação foi exatamente o esquecimento, como descrito em outros trabalhos (Jordan et al., 2000). Considerando que o esquecimento, muitas vezes, é uma forma de rejeição, torna-se maior a necessidade de se adotarem mecanismos que ajudem os pacientes a se engajarem no tratamento. 
Quanto ao uso de outras medicações, em torno da metade dessas medicações são indicadas para o tratamento de patologias concomitantes ao quadro, não relacionadas com infecções oportunistas. Não houve aumento significativo da ocorrência de efeitos colaterais devido ao uso de outros remédios.

O percentual de aderência médio encontrado foi considerado bom, sendo superior ao descrito em outros trabalhos realizados em nosso meio ou em âmbito internacional. No maior estudo brasileiro sobre o tema, em 27 unidades do Estado de São Paulo, a aderência foi de $69 \%$ (Nemes et al., 2000). Também o percentual de pessoas aderentes, considerando os dois pontos de corte definidos neste trabalho, foi superior ao descrito na literatura.

Ressaltamos a importância das variáveis relacionadas à situação sócio-econômica dos pacientes de AIDS na determinação de uma baixa aderência ao tratamento anti-retroviral. Aparentemente, tais variáveis exercem em conjunto um efeito maior na aderência do que aquele decorrente das características da doença em si e do próprio tratamento. As categorias de maior risco foram pessoas com menos de 35 anos, com renda pessoal ou familiar baixa, com nível mais baixo de escolaridade e sem emprego.

A aderência é um processo em que vários fatores têm influências e pesos diversos. Mühlig \& Petermann (1999) ressaltam a influência de fatores decorrentes da natureza da doença, da personalidade do(a) paciente, do seu entorno social, da qualidade da relação da equipe terapêutica com o(a) paciente, das condições do serviço de saúde e de fatores decorrentes do próprio tratamento. Para os autores, o processo deve levar à busca de um consenso em que se atinge o equilíbrio quando se conciliam as expectativas da equipe com as do(a) paciente. A equipe desenvolve conceitos e representações sobre a doença, a terapia e as metas terapêuticas com base nos modelos biomédico e clínico farmacológico. Já o(a) paciente apresenta conceitos e representações sobre esses mesmos aspectos, porém definidos de forma distinta, por meio de vivências subjetivas individuais, do acesso à informação, do contexto cultural em que está imerso(a), da eficácia simbólica das intervenções e do autocuidado, bem como das próprias percepções sobre saúde e qualidade de vida.

Após essas considerações, devem-se salientar algumas limitações ao discutir os resultados: (1) estudou-se uma população definida, fechada, caracterizada por ser atendida em um único serviço de saúde, incluída no trabalho de maneira não aleatória; desse modo, há de se ter precaução ao extrapolar os resultados para a população geral de pacientes; (2) não se dimensionou a influência na qualidade do serviço; (3) visando a se obter parâmetro mais abrangente quanto ao tratamento, considerou-se todo o período de uso da medicação para o cálculo do percentual de aderência. Este fato pode levar a eventuais vieses de memória; (4) considerouse apenas a quantidade de comprimidos ingeridos, e não o seguimento das restrições dietéticas ou o respeito à pontualidade nas tomadas da medicação.

Sob a ótica da promoção à saúde, torna-se evidente que, ao constatar o peso de variáveis relacionadas ao contexto social, os níveis de intervenção abrangem áreas tão diversas como a promoção de ambientes sociais de apoio isentos de estigma e preconceito, a adequada organização dos serviços - incluindo a sensibilização e treinamento das equipes -, além da promoção de atitudes e hábitos saudáveis. Seguindo os outros delineamentos da Carta de Ottawa (MS, 2001), é evidente que os anteriores aspectos pressupõem a disponibilidade do medicamento o que envolve a formulação de políticas públicas prioritárias. Considerando o aumento observado da incidência de HIV nas camadas excluídas da população, os nossos dados vêm reforçar a justificativa do fornecimento da medicação pela rede pública.

As variáveis que avaliam o apoio social, aqui entendido como o suporte no micromeio das relações imediatas do(a) paciente, não apareceram de maneira tão expressiva como as demais variáveis. Apenas o fato de "morar só ou em instituição" se mostrou significativamente associado à baixa aderência, e isso mostra a necessidade de envolver setores da comunidade no processo.

Fica evidente também a necessidade de se desenvolverem estratégias de comunicação e relacionamento do serviço com o paciente, visando ao aumento da aderência. Concluímos que é particularmente importante a participação da equipe multidisciplinar e multiprofissional, e não apenas do profissional da medicina no tratamento, o que implica uma boa organização do serviço. Concordamos com Paiva et al. (2000) em que profissionais da medicina devem dividir a responsabilidade a eles atribuída de informar e orientar os(as) pacientes. Isto poderá otimizar o tempo das consultas e reforçar os objetivos do serviço, melhorando a qualidade da assistência.

Das variáveis relacionadas à doença e ao estado clínico, destaca-se a presença de infecção oportunista no momento do diagnóstico. Das decorrentes do tratamento, a ocorrência de 
efeitos colaterais foi a mais relevante. Novas iniciativas de interação entre pacientes, tais como os clubes de aderência, têm sido implementadas (Paiva et al., 2000 inter alia). Tais estratégias visam a ampliar as redes de apoio para lidar com as dificuldades decorrentes da vivência da doença, aumentar o grau de informação e equilibrar as relações assimétricas de poder na relação com a equipe profissional de saúde.

\section{Referências}

BONNET, F.; MORLAT, P.; CHÊNE, G.; MERCIÉ, P.; NEAU, D.; CHOSSAT, I.; DECOIN, M.; DJOSSOU, F.; BEYLOT, J.; DABIS, F. \& GECSA (Groupe d'Epidémiologie Clinique du Sida en Aquitaine), 2002. Causes of death among HIV-infected patients in the era of anti-retroviral therapy, Bordeaux, France, 1998-1999. HIV Medicine, 3:195199.

CASCADE COLLABORATION (Concerted Action on Sero-Conversion to AIDS and Death in Europe), 2000. Survival after introduction of HAART in people with known duration of HIV-1 infection. Lancet, 355:1158-1159.

CONDRA, J. H. \& EMINI, E. A., 1997. Preventing HIV1 drug resistance. Science \& Medicine, 4:14-23.

COORDENAÇÃO NACIONAL DE DST/AIDS, 2000. Boletim Epidemiológico AIDS, XII(4).

EGGER, M.; HIRSCHEL, B.; FRANCIOLI, P.; SUDRE, P.; WIRTZ, M.; FLEPP, M.; RICKENBACH, M.; MALINVERNI, R.; VERNAZZA, P. \& BATTEGAY, M., 1997. Impact of new anti-retroviral combination therapies in HIV infected patients in Switzerland: Prospective multicentre study. Swiss HIV Cohort Study. BMJ, 315:1194-1199.

FONSECA, M. G. P. \& BARREIRA, D., 2000. A evolução da mortalidade por AIDS no país, segundo sua distribuição geográfica. Boletim Epidemiológico AIDS, XIII(3):43-49.

GRAY, L.; EDMONDSON, E. \& LEMKE, A. L., 1998. HIV Treatment Adherence: A Guide for Program Development. Seattle: HIV/AIDS Project Development and Evaluation Unit, University of Washington, School of Social Work, 1998. 20 November 1999 <http://www.hapdeu.org/adherence>.

HIRSCH, M. S.; CONWAY, B.; D'AQUILA, R. T.; JOHNSON, V. A.; BRUN-VÉZINET, F; CLOTET, B.; DEMETER, L. M.; HAMMER, S. M.; JACOBSEN, D. M.; KURITZKES, D. R.; LOVEDAY, C.; MELLORS, J. W.; VELLA, S. \& RICHMAN, D. D., 1999. Testes de resistência aos agentes anti-retrovirais nos adultos HIV-positivos. JAMA Brasil, 3:1642-1656.
JORDAN, M. S.; LOPES, J. F.; OKAZAKI, E.; KOMATSU, C. L. \& NEMES, M. I. B., 2000. Aderência ao tratamento anti-retroviral em AIDS: Revisão da literatura médica. In: Tá Difícil de Engolir? Experiências de Adesão ao Tratamento Anti-retroviral em São Paulo (P. R. Teixeira, V. Paiva \& E. Shimmma, org.), pp. 5-25, São Paulo: Núcleo de Estudos para Prevenção da AIDS, Universidade de São Paulo/ Programa Estadual DST/AIDS de São Paulo/Coordenação Estadual de DST/AIDS de São Paulo.

LEE, L. M.; KARON, J. M.; SELIK, R.; NEAL, J. J. \& FLEMING, P. L., 2001. Survival after AIDS diagnosis in adolescents and adults during the treatment era, United States, 1984-1997. JAMA, 285: 1308-1315.

LEMES, C., 1998. Trégua Ameaçada. São Paulo: Sociedade Brasileira de Medicina Tropical.

MOCROFT, A.; BRETTLE, R.; KIRK, O.; PARKIN, J. M.; ANTUNES, F; FRANCIOLI, P.; D'ARMINIO-MONFORTE, A.; FOX, Z.; LUNDGREN, J. D. \& THE EURO-SIDA STUDY GROUP, 2002. Changes in the cause of death among HIV positive subjects across Europe: Results from the EuroSIDA Study. AIDS, 16:1663-1671.

MOUTON, Y.; ALFANDARI, S.; VALETTE, M.; CARTIER, F.; DELLAMONICA, P.; HUMBERT, G.; LANG, J. M.; MASSIP, P.; MECHALI, D.; LECLERCQ, P.; MODAI, J. \& PORTIER, H., 1997. Impact of protease inhibitors on AIDS-defining events and hospitalizations in 10 French AIDS reference centers. Federation Nationale des Centres de Lutte contre le SIDA. AIDS, 11:F101-F105.

MS (Ministério da Saúde), 2001. Carta de Ottawa. In: Promoção da Saúde (MS, org.), Brasília: MS.

MÜHLIG, S. \& PETERMANN, F., 1999. Compliance zwischen Therapiegehorsam und Therapiepartnerschaft. In: Compliance und Anti-retrovirale Therapie (AIDS-Forum DAH, org.), pp. 61-74, Berlin: AIDS-Hilfe.

NEMES, M. I. B.; SOUZA, M. F. M.; KALICHMAN, A. O.; GRANGEIRO, A.; SOUZA, R. A. \& LOPES, J. F., 2000. 
Avaliação da Aderência ao Tratamento por Antiretrovirais em Usuários de Ambulatórios do Sistema Público de Assistência à AIDS no Estado de São Paulo. 19 Março $2000<$ http://www.aids.gov. $\mathrm{br} /$ planejamento/não_aderência.htm>.

PAIVA, V.; LEME, B.; NIGRO, R. \& CARACIOLO, J., 2000. Lidando com a adesão - A experiência de profissionais e ativistas na cidade de São Paulo. In: Tá Difícil de Engolir? Experiências de Adesão ao Tratamento Anti-retroviral em São Paulo (P. R. Teixeira, V. Paiva \& E. Shimmma, org.), pp. 27-78, São Paulo: Núcleo de Estudos para Prevenção da AIDS, Universidade de São Paulo/Programa Estadual DST/AIDS de São Paulo/Coordenação Estadual de DST/AIDS de São Paulo.

PALELLA Jr., F. J.; DELANEY, K. M.; MOORMAN, A. C.; LOVELESS, M. O.; FUHRER, J.; SATTEN, G. A.; ASCHMAN, D. J. \& HOLMBERG, S. D., 1998. Declining morbidity and mortality among patients with advanced human immunodeficiency virus infection. HIV Outpatient Study Investigators. New England Journal of Medicine, 338:853-860.

RIERA, M.; DE LA FUENTE, L.; PUIGVENTOS, F; VILLALONGA, C.; SALAS, A.; PAREJA, A. \& DE LA PEÑA, A., 1999. Accuracy of different indirect methods to detect anti-retroviral adherence needed to obtain a good viral control at 9 months of follow-up. In: Seventh European Conference on Clinical Aspects and Treatment of HIV-Infection, Abstract Book, p. 127, Lisbon: European AIDS Clinical Society.
SANTOS, C. P.; NASCIMENTO, V. L. V. \& FELIPE, Y. X. 2000. Aderência ao tratamento anti-retroviral: Resultados preliminares e reflexões da experiência em um serviço universitário - Casa da AIDS. In: Tá Difícil de Engolir? Experiências de Adesão ao Tratamento Anti-retroviral em São Paulo (P. R. Teixeira, V. Paiva \& E. Shimmma, org.), pp. 115127, São Paulo: Núcleo de Estudos para Prevenção da AIDS, Universidade de São Paulo/Programa Estadual DST/AIDS de São Paulo/Coordenação Estadual de DST/AIDS de São Paulo.

SES-DF (Secretaria de Saúde do Distrito Federal), 2000. Programa de controle da DST/AIDS do Distrito Federal. Boletim Epidemiológico de DST/AIDS do Distrito Federal, 03/99.

SUMARTOJO, E., 1993. When tuberculosis treatment fails - A social behavioral account of patient adherence. American Review of Respiratory Disease, 147:1311-1320.

VALE, M. S., 1999. Avaliação da Aderência ao Tratamento de Pacientes com HIVIAIDS no Centro de Saúde de Taguatinga № 4, Outubro - Dezembro de 1998. Monografia de Especialização, Brasília: Universidade de Brasília.

WOLFF, M.; DIOMEDI, A.; MORALES, O.; BIDART, T.; DABANCH, J.; BUSTAMANTE, C. \& NORTHLAND, R., 2001. Prospective follow-up of a HIV-infected population with and without access to anti-retroviral therapy: Impact on survival and complications. Revista Médica de Chile, 129:886-894.

Recebido em 17 de outubro de 2001

Versão final reapresentada em 1 de outubro de 2002 Aprovado em 17 de dezembro de 2002 